\title{
Alterstice
}

Revue internationale de la recherche interculturelle

International Journal of Intercultural Research

Revista International de la Investigacion Intercultural

\section{Témoigner... pour les sciences sociales et humaines}

\section{Yvan Leanza}

Volume 1, numéro 2, 2011

URI : https://id.erudit.org/iderudit/1077597ar

DOI : https://doi.org/10.7202/1077597ar

Aller au sommaire du numéro

Éditeur(s)

Alterstice

ISSN

1923-919X (numérique)

Découvrir la revue

Citer ce document

Leanza, Y. (2011). Témoigner... pour les sciences sociales et humaines. Alterstice, 1(2), 1-2. https://doi.org/10.7202/1077597ar d'utilisation que vous pouvez consulter en ligne. 


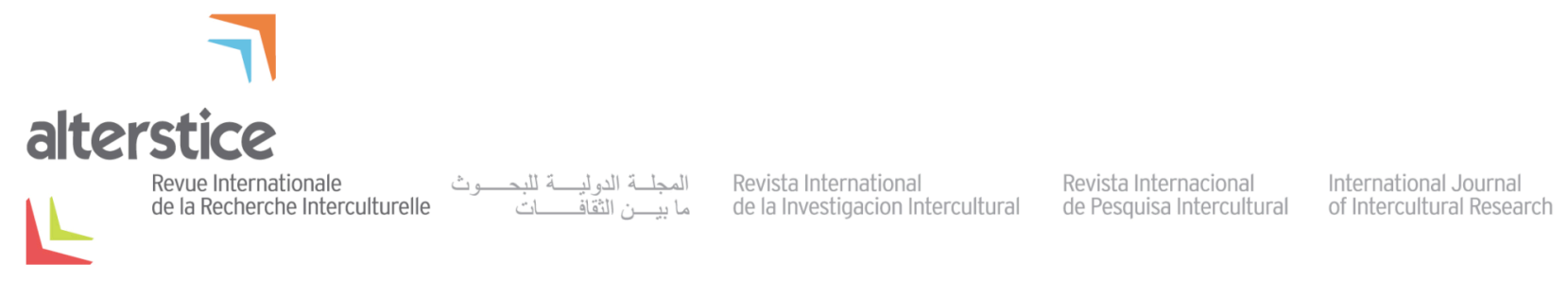

ÉDITORIAL

\section{Témoigner... pour les sciences sociales et humaines}

Yvan Leanza $^{1}$

Avec ce numéro, Francine Saillant et ses invités abordent un thème fondamental mais négligé, celui de la reproduction et de l'usage de la parole ou de l'image de l'Autre dans diverses sphères de la vie sociale et politique. Comme le présente Saillant dans son introduction, observer, décrire et analyser les formes de témoignages employés par différents acteurs sociaux, en particulier ceux qui défendent officiellement les plus vulnérables, amène à réfléchir sur l'altérité telle qu'elle est véhiculée, entretenue dans les sociétés les plus riches ou telle qu'elle est vécue ailleurs. Cet exercice permet aussi de mettre en évidence les processus "d'altérisation » : est-ce que le témoignage est une parole qui transforme ou une parole transformée dans un but bien déterminé ? Avec un tel thème, on se situe bien dans l'alterstice, cet entre-deux qui transforme.

Ce numéro d'Alterstice est aussi un témoignage en lui-même. À l'heure où j'écris ces lignes, de nombreux dirigeants des pays de l'OCDE mettent en application des politiques rigoristes (pensées déjà dans les années 1980 et 1990) de réduction des ressources pour les sciences qui ne produisent pas... pardon... pour les sciences dont l'efficience (soit le rapport entre le coût de production et la valeur ajoutée du produit fini) n'est pas démontrée. Pire, ils s'engagent, plus ou moins explicitement, à transformer l'Université en une entreprise marchande avec des clients (les étudiants ou les entreprises en demande de formation et de capacité de recherche) et des représentants à la clientèle (les professeurs et autres enseignants). Ce n'est plus seulement la connaissance que l'on veut vendre, mais bien les différentes composantes de l'Université elle-même. En effet, pourquoi investir dans la formation de lettrés qui ne sauront manier un spectrographe de masse, dessiner les plans d'un pont, établir le bilan financier d'une multinationale ou ouvrir une mine ? Pourquoi disperser des ressources dans le maintien de programmes d'enseignement universitaire qui n'intéressent finalement qu'une poignée de penseurs un peu loufoques? 
La réponse : c'est évidemment pour entretenir et développer la capacité de penser dans le sens premier du terme, soit construire des idées par la réflexion. Construire des idées, pas ânonner du prêt-à-penser. Poser un regard critique sur le monde et non confirmer le discours et la place des puissants. Il est nécessaire, pour toute société démocratique, de faire exister un tel lieu de liberté de pensée et de création. C'est certes un lieu privilégié et nécessairement diversifié, métissé, qui se doit d'appliquer des règles de vie commune et entretenir des liens avec l'ensemble de la société, mais ce cadre ne doit pas être un carcan ou mis au service d'intérêts particuliers (ceux des puissants). Cela semblait acquis, mais ce privilège et les capacités qu'il génère en rendent plus d'un envieux et d'autres se sentent menacés.

Alterstice est une émanation du monde universitaire, un espace de débat autour de thèmes sensibles. Un espace multicentrique. Faire du témoignage le thème central de ce numéro, c'est un peu une mise en abîme : la revue témoigne (et témoignera) de l'indispensable apport des sciences moins rentables d'un point de vue comptable, mais particulièrement rentables pour la construction de pensées originales et transformatrices.

\section{Rattachement de l'auteur}

${ }^{1}$ Université Laval, Québec, Canada

\section{Correspondance}

alterstice@gmail.com

\section{Pour citer cet article :}

Leanza, Y. (2011). Témoigner... pour les sciences sociales et humaines [Éditorial]. Alterstice, 1(2), 1-2. 